\title{
Parâmetros nutricionais e estabilidade aeróbia de silagens de cereais de inverno submetidas a diferentes regimes de corte no estádio vegetativo
}

\author{
[Cutting system in vegetative stage alters nutritional parameters and aerobic stability of \\ Winter cereals silage] \\ G.F.M. Leão ${ }^{1}$, C.C. Jobim ${ }^{1}$, M. Neumann ${ }^{2}$, A.V.I. Bueno ${ }^{1}$, M.G. Ribeiro ${ }^{1}$, F.A. Jacovaci ${ }^{1}$, \\ E.H. Horst ${ }^{2}$, M.R.H. Silva ${ }^{2}$, E.J. Askel ${ }^{2}$ \\ ${ }^{1}$ Universidade Estadual de Maringá - Maringá, PR \\ ${ }^{2}$ Universidade Estadual do Centro Oeste - Guarapuava, PR
}

\begin{abstract}
RESUMO
O uso de regimes de corte em estádio vegetativo para os cereais de inverno é interessante quando se busca intensificar a produção de alimento volumoso para ruminantes. No entanto, é necessário se averiguar o impacto desse manejo sobre as características das silagens resultantes. Dessa forma, o objetivo do experimento foi avaliar o valor nutricional e a estabilidade aeróbia de silagens de cereais de inverno, submetidas a regimes de corte no estádio vegetativo, prévio ao corte para ensilagem. Os cereais utilizados foram trigo (Triticum aestivum cv. BRS Gralha Azul), cevada (Hordeum vulgare cv. BRS Brau), aveia-branca (Avena sativa cv. URS Guará), aveia- preta (Avena strigosa cv. Embrapa 139) e triticale ( $X$ Triticosecale cv. IPR 11), associados a três regimes de corte: sem cortes prévios (silagem exclusiva); um corte; e com dois cortes em estádio vegetativo e subsequente produção de silagem. Na avaliação nutricional, a cevada apresentou valores baixos de FDA (311,7 e $\left.375,3 \mathrm{~g} \mathrm{~kg} \mathrm{de} \mathrm{MS}^{-1}\right)$ e altos de NDT $\left(569,2\right.$ e 533,4g kg de $\left.\mathrm{MS}^{-1}\right)$ para os sistemas com um e dois cortes, respectivamente. Na avaliação da estabilidade aeróbia, os materiais foram bastante estáveis após a abertura dos silos, com exceção da aveia-branca e da aveia-preta, no regime sem cortes. As silagens de triticale e de cevada apresentaram as maiores estabilidades nutricionais com o aumento no número de cortes.
\end{abstract}

Palavras-chave: cevada, proteína, trigo, triticale

\begin{abstract}
The use of cutting regimes in vegetative stage for winter cereals is interesting when it seeks to intensify the forage production for ruminants. However, it is necessary to ascertain the impact of this management on the characteristics of the resulting silage. Thus, the aim of the experiment was to evaluate the nutritional quality and aerobic stability of winter cereal silages submitted to cutting regimes in vegetative stage, before ensiling. The materials used were: wheat (Triticum aestivum cv. BRS Gralha Azul); barley (Hordeum vulgare cV. BRS Brau); white oat (Avena sativa cv. URS Guará); black oat (Avena strigosa cv. Embrapa 139) and triticale (X Triticosecale cV IPR 11); associated with three management strategies: without previous cuts (Only silage), one cut and two cuts in vegetative and posterior silage making. Barley owned low values of ADF (311.7 and $375.3 \mathrm{~g} \mathrm{~kg} \mathrm{de} \mathrm{DM}^{-1}$ ) and high TDN (569.2 and 533.4g kg de $\mathrm{DM}^{-1}$ ) for one and two-cut system, respectively. For aerobic stability, materials were quite stable after opening the silos, with the exception of black and white oat in management without cuts. Triticale and barley silage had the highest nutritional stability with the increase in the number of cuts.
\end{abstract}

Keywords: barley, protein, triticale, wheat

\section{INTRODUÇ̃̃O}

As condições climáticas encontradas na região Sul do Brasil possibilitam o cultivo de cereais de inverno, permitindo um melhor aproveitamento

Recebido em 8 de abril de 2016

Aceito em 20 de junho de 2016

E-mail: gfleao@hotmail.com de recursos, como terra, infraestrutura e mão de obra (Rosário et al., 2012). Esses materiais possuem grande versatilidade, podendo ser aproveitados para a alimentação animal tanto no estádio vegetativo, sendo usado para forrageamento direto (Nascimento Jr. et al., 
2013), quanto no estádio reprodutivo, voltado para a produção de grãos e seus usos em rações ou para a produção de silagem (Bortolini et al., 2004).

Embora o uso das silagens de cereais de inverno seja incipiente no Brasil, na Europa seu uso passou de "cultura esporádica" para "cultura de base", dado seu excelente valor alimentício e suas boas qualidades de conservação, apresentando, inclusive, bons aspectos produtivos (Bumbieris Jr. et al., 2011).

Com isso, despertou-se o interesse no desenvolvimento de estratégias para melhor uso dessas culturas. Uma dessas estratégias seria associar cortes no período vegetativo com posterior diferimento da área para produção de silagem, gerando um aproveitamento em duplo propósito. Embora alguns estudos tenham sido conduzidos nesse contexto (Hastenpflung et al., 2011; Carletto et al., 2015), sobretudo com o trigo, na literatura há poucos indícios do impacto do número de cortes no período vegetativo sobre os aspectos nutricionais e a estabilidade aeróbica das silagens. Somado a isso, outros cereais com potencial de produção de forragem deveriam ser avaliados, na busca pela escolha do material com melhor adaptabilidade a essa estratégia.

Assim, o objetivo do presente trabalho foi avaliar o valor nutricional e a estabilidade aeróbia de silagens de cereais de inverno submetidas a regimes de corte no estádio vegetativo e a posterior produção de silagem.

\section{MATERIAL E MÉTODOS}

O experimento foi conduzido no Núcleo de Produção Animal (Nupran), pertencente ao Setor de Ciências Agrárias e Ambientais da Universidade Estadual do Centro-Oeste (Unicentro), localizado no município de Guarapuava - PR, situado na zona subtropical do Paraná sob as coordenadas geográficas $25^{\circ} 23^{\prime} 02 "$ de latitude sul e 51 29 ' $43^{\prime \prime}$ de longitude oeste e $1.026 \mathrm{~m}$ de altitude. O clima da região, segundo a classificação de Köppen, é o $\mathrm{Cfb}$ (subtropical mesotérmico úmido), com verões amenos e inverno moderado, sem estação seca definida e com geadas severas. A precipitação média anual é de $1944 \mathrm{~mm}$, temperatura média mínima anual de $12,7^{\circ} \mathrm{C}$, temperatura média máxima anual de $23,5^{\circ} \mathrm{C}$ e umidade relativa do ar de 77,9\% (Cartas..., 2000).

O solo da área experimental é classificado como Latossolo Bruno Típico, e, em ocasião antecipada ao plantio, apresentou as seguintes características químicas (perfil de 0 a $20 \mathrm{~cm}$ ): $\mathrm{pH}$ $\mathrm{CaCl}_{2}$ 0,01M: 4,7; P: 1,1mg dm${ }^{-3} ; \mathrm{K}^{+}: 0,2 \mathrm{cmol}_{\mathrm{c}}$ $\mathrm{dm}^{-3}$; MO: $2,62 \% ; \mathrm{Al}^{3+}: 0,0 \mathrm{cmol}_{\mathrm{c}} \mathrm{dm}^{-3} ; \mathrm{H}^{+}+\mathrm{Al}^{3+}$ : $5,2 \mathrm{cmol}_{\mathrm{c}} \mathrm{dm}^{-3} ; \mathrm{Ca}^{2+}: 5,0 \mathrm{cmol}_{\mathrm{c}} \mathrm{dm}^{-3} ; \mathrm{Mg}^{2+}$ : $5,0 \mathrm{cmol}_{\mathrm{c}} \mathrm{dm}^{-3}$ e saturação de bases: $67,3 \%$.

Como material experimental, utilizou-se trigo (Triticum aestivum cv. BRS Gralha Azul), cevada (Hordeum vulgare cv. BRS Brau), aveiabranca (Avena sativa cv. URS Guará), aveiapreta (Avena strigosa cv. Embrapa 139) e triticale ( $X$ Triticosecale cv. IPR 11), e esses materiais foram submetidos a três regimes de corte: sendo uma área sem cortes (silagem exclusivo); com um corte; e com dois cortes em estádio vegetativo. Após a realização desses cortes, as áreas foram vedadas visando à produção de silagem.

O campo experimental constituiu-se de uma área total de $225 \mathrm{~m}^{2}$, distribuída em 75 parcelas de $3 \mathrm{~m}^{2}$ cada $(3 \mathrm{~m} \times 1 \mathrm{~m})$, onde foi utilizada área útil de $1,60 \mathrm{~m}^{2}(1 \mathrm{~m} \mathrm{x} \mathrm{1,6m)}$ para as avaliações. Cada parcela representou uma unidade experimental (repetição). A semeadura no campo experimental ocorreu no dia 03 de junho de 2014, em sistema de plantio direto por meio de semeadora modelo Semeato SHM 15/17 com a mesma densidade para todas as culturas. No plantio, o espaçamento entre linhas foi de $0,17 \mathrm{~m}$, e a profundidade de semeadura foi de $0,04 \mathrm{~m}$, com distribuição de 400 sementes por $\mathrm{m}^{2}$.

Por ocasião da semeadura, realizou-se a adubação de base com $300 \mathrm{~kg} \mathrm{ha}^{-1}$ do fertilizante formulado 08-30-20 (N- $\left.\mathrm{P}_{2} \mathrm{O}_{5}-\mathrm{K}_{2} \mathrm{O}\right)$, respeitando recomendações da comissão de fertilidade do solo de Santa Catarina e do Rio Grande do Sul (2004). A adubação nitrogenada de cobertura foi feita em uma única aplicação, 30 dias após o plantio, com $196 \mathrm{~kg} \mathrm{ha}^{-1}$ de ureia (46-00-00), o que totalizou $90 \mathrm{~kg} \mathrm{ha}^{-1}$ de nitrogênio.

As plantas daninhas foram controladas quimicamente com o uso de herbicidas, primeiramente na dessecação da área experimental realizada no dia 10 de maio de 2014, utilizando-se herbicida à base de Glifosate 
(produto comercial Roundup $\mathrm{WG}^{\circledR}: 3,0 \mathrm{~kg} \mathrm{ha}^{-1}$ ); já no manejo da cultura, 30 dias após o plantio, foi efetuada a aplicação do herbicida à base de metsulfuron-metyl (produto comercial Ally ${ }^{\circledR}$ : $\left.6,6 \mathrm{~g} \mathrm{ha}^{-1}\right)$. O controle de pragas foi realizado até 30 dias após a emergência das plantas, de acordo com avaliações de campo, indicando o ponto de dano econômico, sendo utilizado o inseticida à base de imidacloprido + beta-ciflutrina (produto comercial Connect ${ }^{\circledR}$ : $500 \mathrm{~mL} \mathrm{ha}^{-1}$ ). Para o controle preventivo de doenças fúngicas, foi necessário o emprego de fungicida à base de propiconazol (produto comercial Tilt ${ }^{\circledR}: 750 \mathrm{~mL}$ $\mathrm{ha}^{-1}$ ). Todas as aplicações químicas foram realizadas mediante laudo técnico das lavouras.

O regime de manejo nos tratamentos submetidos a um corte ou a dois cortes no estádio vegetativo seguiu recomendações de Fontaneli et al. (2009), ou seja, os cortes foram realizados quando as plantas, em cada tratamento, atingiram altura média de $30 \mathrm{~cm}$, sendo estas rebaixadas a $8 \mathrm{~cm}$ da superfície do solo.

As silagens, para cada cultura, foram produzidas quando as plantas atingiram o estádio de grão farináceo, momento indicado para a ensilagem, de acordo com Fontaneli et al. (2009). Nesse contexto, para o regime sem corte, as silagens de trigo, triticale e cevada foram produzidas aos 115 DAP (dias após o plantio - 27 de setembro de 2014), enquanto as silagens de aveia-branca e aveia-preta foram produzidas aos 121 DAP (4 de outubro de 2014). Para o sistema com um corte, as silagens de trigo, triticale e cevada foram produzidas aos 135 DAP (18 de outubro de 2014), enquanto as silagens de aveia-branca e aveia-preta foram produzidas aos 142 DAP (25 de outubro de 2014). Para o sistema com dois cortes, as silagens de trigo, triticale e cevada foram produzidas aos 153 DAP (6 de novembro de 2014), enquanto a aveia-branca e a aveia-preta foram produzidas aos 161 DAP (15 de novembro de 2014).

No momento da ensilagem, as plantas de cada parcela foram colhidas a $8 \mathrm{~cm}$ da superfície do solo e, posteriormente, os materiais foram processados em picador de forragem estacionário, modelo EM 6400 da marca Nogueira ${ }^{\circledR}$ e ensilados em silos experimentais. Após o processamento, foi observado tamanho médio de partícula de $3,7 \mathrm{~cm}$, determinado segundo metodologia descrita por Jobim et al. (2007).

Os silos foram tubos de $\mathrm{PVC}$, com $10 \mathrm{~cm}$ de diâmetro $\times 50 \mathrm{~cm}$ de altura e capacidade para cerca de $3 \mathrm{~kg}$, compactados de forma manual e devidamente identificados com etiquetas. Para vedação dos silos, foram utilizadas lona preta e fita adesiva. Após a ensilagem, os silos foram armazenados em área coberta, por um período de 60 dias, quando foram abertos, e uma amostra de $500 \mathrm{~g}$ de cada tratamento foi acondicionada em estufa para a determinação de MS. Posteriormente, a amostra foi encaminhada para a análise química conforme Silva e Queiroz (2009).

As avaliações da estabilidade aeróbia (EA), por sua vez, foram obtidas por meio de medidas de temperatura e de $\mathrm{pH}$, as quais foram iniciadas após a abertura dos silos. Em cada silo, a silagem foi descompactada para facilitar a exposição do material ensilado ao ar, conforme descrito por Kung Jr. et al. (2000), e o material foi alocado em baldes com capacidade para $4 \mathrm{~kg}$. O período de avaliação teve duração de 168 horas (em torno de sete dias após abertura dos silos).

Os baldes foram acondicionados em sala com controle de temperatura, programada para permanecer em temperatura constante de $25^{\circ} \mathrm{C}$, durante todo o período experimental. Para determinar a EA das silagens, foi realizada a leitura da temperatura das silagens diretamente nos baldes, utilizando-se um termômetro digital de haste longa, modelo Gulterm 1001, inserido no centro da massa da forragem. As leituras de temperatura foram realizadas diariamente, às seis , 12 e 18 horas, juntamente com as leituras de $\mathrm{pH}$. As leituras de $\mathrm{pH}$ foram feitas mediante o uso de potenciômetro digital, de acordo com a metodologia estabelecida por Cherney e Cherney (2003).

Como critério para definição de quebra de estabilidade aeróbia, foi considerado quando a temperatura do material ensilado ultrapassava em $2^{\circ} \mathrm{C}$ a temperatura do ambiente, conforme orientação de Taylor e Kung Jr. (2002), ou quando o $\mathrm{pH}$ aumentava em níveis acima de 0,5 unidades em até cinco dias, conforme citado por Weinberg et al. (2008). Com a mensuração desses parâmetros, foi possível determinar a estabilidade aeróbia (tempo em horas para 
quebra), a média das temperaturas, assim como a média do $\mathrm{pH}$ durante o período de aeração.

As amostras pré-secas das silagens de cereais de inverno foram moídas a $1 \mathrm{~mm}$ em moinho tipo Willey, onde sequencialmente se determinou a matéria seca total em estufa a $105^{\circ} \mathrm{C}$ por 16 horas, a proteína bruta $(\mathrm{PB})$ pelo método microKjeldahl e a matéria mineral (MM) por incineração a $550^{\circ} \mathrm{C}$ por quatro horas (Silva e Queiroz, 2009). Foram determinados os teores de fibra em detergente neutro (FDN), conforme Van Soest et al. (1991), utilizando-se $\alpha$-amilase termoestável (Termamyl 120L, Novozymes Latin América Ltda.), fibra em detergente ácido (FDA), segundo Goering e Van Soest (1970), e os teores de hemicelulose por diferença (HEM = FDN - FDA), seguindo metodologia proposta por Silva e Queiroz (2009). O teor de nutrientes digestíveis totais (NDT) na forragem foi estimado segundo a equação NDT $=74,49$ $0,5635^{*}$ FDA $\left(\mathrm{R}^{2}=0,84\right)$, descrita por Cappelle et al. (2001) para volumosos.

O delineamento experimental empregado foi o de blocos ao acaso, em arranjo fatorial composto por cinco espécies de cereais de inverno (trigo, triticale, cevada, aveia-branca e aveia-preta), três regimes de corte em estádio vegetativo (sem cortes, com um corte e com dois cortes) e cinco repetições. Os resultados obtidos foram submetidos à análise de variância e comparados utilizando-se o teste de Tukey ao nível de 5\% de significância, por intermédio do programa estatístico Statistical... (1993).

\section{RESULTADOS E DISCUSSÃO}

Com relação ao valor nutricional, pode-se observar que houve interação significativa $(\mathrm{P}<0,05)$ entre os cereais de inverno e o número de regimes de corte a que foram submetidos no estádio vegetativo (Tab. 1).

Constatou-se que o trigo foi o material que apresentou o maior teor de MS dentre todos os cereais para o regime sem cortes e com um corte. Para o sistema com dois cortes, o trigo e a cevada apresentaram os maiores valores de MS. Essa diferença no teor de MS entre os cereais avaliados pode ser decorrente do seu genótipo, o qual tem influência no acúmulo de MS dos materiais (Lehmen et al., 2014). Entre os regimes de corte, para todos os cereais, foi possível observar um aumento nos teores de MS com o aumento no número de cortes, e tal achado é decorrente do alongamento do ciclo dos materiais, o que, consequentemente, faz com que se aumente o teor de MS (Bortolini et al., 2004).

De acordo com os dados encontrados, para o sistema sem cortes, observa-se que a aveia-preta e o trigo apresentaram maiores teores de FDN. Para a aveia-preta, os resultados são bastante semelhantes aos observados em literatura. A exemplo, os resultados do presente trabalho foram intermediários aos encontrados por Lehmen et al. (2014) e Meinerz et al. (2011) (745,0g kg e 695,9g g de $\mathrm{MS}^{-1}$, respectivamente). Notadamente, essa característica de alto teor de FDN da aveia-preta é bastante conciso em literatura, o que, inclusive, é um dos fatores que conferem a essa forragem grande rusticidade $\mathrm{e}$ maior resistência a doenças foliares (Carvalho et al., 2013).

Por outro lado, os valores de FDN observados no trigo divergem da literatura. Lehmen et al. (2014), ao avaliare três genótipos, observaram para o trigo valores médios de $636,6 \mathrm{~g} \mathrm{~kg}$ de $\mathrm{MS}^{-}$ 1 , cerca de $13,10 \%$ menor que os resultados médios encontrados no presente trabalho. Em consonância, Meinerz et al. (2011) também observaram valores inferiores de FDN para essa cultura $\left(616,8 \mathrm{~g} \mathrm{~kg}\right.$ de $\left.\mathrm{MS}^{-1}\right)$, cerca de $15,80 \%$ menor que os resultados encontrados neste trabalho.

Com relação aos efeitos dos regimes de corte sobre os teores de FDN, pode-se observar que houve efeito para o triticale, a cevada e a aveiapreta, e nos dois primeiros houve característica de aumento nos teores, enquanto houve redução para o último. O aumento nos teores de FDN denota o consumo de carboidratos de reserva para a rebrota dos cereais, o que, por concentração, leva ao aumento dos teores de carboidratos fibrosos (Bortolini et al., 2004). Para a aveia-preta, este efeito foi mais pronunciado para um corte, não gerando tais complicações para o regime com dois cortes. Este comportamento não é desejável, pois teores de FDN elevados podem impactar na repleção do trato gastrointestinal, podendo gerar limitação no consumo dos ruminantes (Nussio et al., 2011). 
Tabela 1. Composição nutricional de silagens de cereais de inverno submetidos a regimes de corte em estádio vegetativo e ensilados em estádio de grão farináceo mole

\begin{tabular}{|c|c|c|c|c|c|}
\hline \multirow{2}{*}{ Regime de cortes } & \multicolumn{5}{|c|}{ Cereais de inverno } \\
\hline & Trigo & Triticale & Cevada & Aveia- branca & Aveia- preta \\
\hline & \multicolumn{5}{|c|}{ Matéria seca, $\mathrm{g} \mathrm{kg} \mathrm{de} \mathrm{MN}^{-1}$} \\
\hline Sem cortes & $298,7 \mathrm{Aa}$ & $272,0 \mathrm{Bb}$ & $227,9 \mathrm{Cc}$ & $225,7 \mathrm{Bc}$ & $22,80 \mathrm{Cc}$ \\
\hline Um corte & $342,0 \mathrm{Ba}$ & $298,0 \mathrm{Bb}$ & $287,3 \mathrm{Bbc}$ & $253,8 \mathrm{Bc}$ & $290,2 \mathrm{Bbc}$ \\
\hline \multirow[t]{2}{*}{ Dois cortes } & $452,8 \mathrm{Ca}$ & $366,8 \mathrm{Ab}$ & $420,9 \mathrm{Aa}$ & $325,0 \mathrm{Ab}$ & $350,8 \mathrm{Ab}$ \\
\hline & \multicolumn{5}{|c|}{ Fibra em detergente neutro, $\mathrm{g}$ kg de $\mathrm{MS}^{-1}$} \\
\hline Sem cortes & $732,6 a$ & $664,2 \mathrm{Bb}$ & $654,6 \mathrm{Bb}$ & $651,7 \mathrm{~b}$ & $729,8 \mathrm{Ba}$ \\
\hline Um corte & $704,3 b$ & $646,7 \mathrm{Bc}$ & $663,2 \mathrm{Bc}$ & $675,3 b c$ & $781,7 \mathrm{Aa}$ \\
\hline \multirow[t]{2}{*}{ Dois cortes } & $685,4 \mathrm{bc}$ & 701,6Aabc & $748,5 \mathrm{Aa}$ & $677,3 \mathrm{c}$ & $728,1 \mathrm{Bab}$ \\
\hline & \multicolumn{5}{|c|}{ Fibra em detergente ácido, $\mathrm{g}$ kg de $\mathrm{MS}^{-1}$} \\
\hline Sem cortes & $381,2 \mathrm{Bc}$ & $412,2 \mathrm{bc}$ & $379,4 \mathrm{c}$ & $436,9 \mathrm{Ab}$ & $507,0 \mathrm{Aa}$ \\
\hline Um corte & $388,2 \mathrm{Ba}$ & $386,4 \mathrm{a}$ & $311,7 b$ & $394,7 \mathrm{Ba}$ & $426,5 \mathrm{Ca}$ \\
\hline \multirow[t]{2}{*}{ Dois cortes } & $421,1 \mathrm{Ab}$ & $411,3 b$ & $375,3 \mathrm{c}$ & $419,6 \mathrm{Ab}$ & $479,7 \mathrm{Ba}$ \\
\hline & \multicolumn{5}{|c|}{ Hemicelulose, g kg de $\mathrm{MS}^{-1}$} \\
\hline Sem cortes & $351,4 \mathrm{Aa}$ & $266,9 b c$ & $275,2 \mathrm{Bb}$ & $214,8 \mathrm{Bc}$ & $222,8 \mathrm{Bbc}$ \\
\hline Um corte & $304,7 \mathrm{ABab}$ & $279,7 b$ & $315,2 \mathrm{ABab}$ & $280,5 \mathrm{Ab}$ & $355,2 \mathrm{Aa}$ \\
\hline \multirow[t]{2}{*}{ Dois cortes } & $264,3 \mathrm{Bb}$ & $290,3 b$ & $373,2 \mathrm{Aa}$ & $257,6 \mathrm{ABb}$ & $248,9 \mathrm{Bb}$ \\
\hline & \multicolumn{5}{|c|}{ Proteína bruta, $\mathrm{g} \mathrm{kg} \mathrm{de} \mathrm{MS}^{-1}$} \\
\hline Sem cortes & $74,8 \mathrm{Aabc}$ & $77,9 \mathrm{ab}$ & $83,5 \mathrm{ABa}$ & $64,5 \mathrm{c}$ & $68,0 \mathrm{bc}$ \\
\hline Um corte & $73,5 \mathrm{ABab}$ & $71,3 \mathrm{ab}$ & $88,1 \mathrm{Aa}$ & $63,9 b$ & $60,5 b$ \\
\hline \multirow[t]{2}{*}{ Dois cortes } & $66,9 \mathrm{Bab}$ & $75,1 \mathrm{a}$ & $75,4 \mathrm{Ba}$ & $60,7 \mathrm{~b}$ & $59,5 \mathrm{~b}$ \\
\hline & \multicolumn{5}{|c|}{ Matéria mineral, $\mathrm{g} \mathrm{kg} \mathrm{de} \mathrm{MS}^{-1}$} \\
\hline Sem cortes & $31,6 \mathrm{Bbc}$ & $30,4 \mathrm{c}$ & $42,3 \mathrm{a}$ & $38,2 \mathrm{Bab}$ & $39,5 \mathrm{ABa}$ \\
\hline Um corte & $30,4 \mathrm{~B}$ & 32,6 & 39,1 & $37,9 \mathrm{~B}$ & $36,1 \mathrm{~B}$ \\
\hline \multirow[t]{2}{*}{ Dois cortes } & $37,0 \mathrm{Abc}$ & $34,1 \mathrm{c}$ & $40,2 \mathrm{abc}$ & $46,1 \mathrm{Aa}$ & $42,4 \mathrm{Aab}$ \\
\hline & \multicolumn{5}{|c|}{ Nutrientes digestíveis totais, $\mathrm{g} \mathrm{kg}$ de $\mathrm{MS}^{-1} *$} \\
\hline Sem cortes & $530,0 \mathrm{Aa}$ & $512,5 \mathrm{ab}$ & $531,0 \mathrm{a}$ & $498,6 \mathrm{Bb}$ & $459,2 \mathrm{Cc}$ \\
\hline Um corte & $526,1 \mathrm{Ab}$ & $527,1 \mathrm{~b}$ & $569,2 \mathrm{a}$ & $522,4 \mathrm{Ab}$ & $504,5 \mathrm{Ab}$ \\
\hline Dois cortes & $507,6 \mathrm{Bb}$ & $513,1 \mathrm{~b}$ & $533,4 \mathrm{a}$ & $508,4 \mathrm{Bb}$ & $474,5 \mathrm{Bc}$ \\
\hline
\end{tabular}

MN: matéria natural. MS: matéria seca. Médias seguidas de letras maiúsculas na coluna e minúsculas na linha diferem entre si pelo teste de Tukey a $5 \%$. NDT $(\%)=74,49-(0,5635 *$ FDA $)$.

Em comparação com os valores de FDA, observou-se que o trigo mostrou os menores valores observados juntamente com a cevada, enquanto os maiores valores desse parâmetro foram observados para aveia-preta. Isso se justifica pela maior quantidade de hemicelulose observada no trigo. Esse teor de hemicelulose, em comparação com a literatura, foi $25,09 \%$

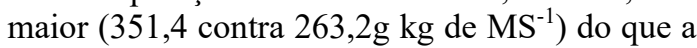
média dos genótipos de trigo avaliados por Meinerz et al. (2011).

Com o aumento no número de cortes, houve aumento no teor de FDA para o trigo, enquanto para a aveia-branca e a aveia-preta houve redução com posterior aumento nos teores. O aumento da FDA, nos tratamentos com cortes no estádio vegetativo, para a silagem de trigo, demonstra que ocorreu um efeito de concentração dos carboidratos fibrosos em consequência do consumo de carboidratos solúveis para que fosse possível a rebrota. Ademais, o próprio estádio de desenvolvimento das culturas contribui para isso, sendo que uma planta mais velha possui maior espessamento e lignificação da parede celular, gerando tais alterações (Carvalho e Pires, 2008). Tal efeito para ambas as aveias não foi tão marcante, sendo que para o regime com um corte houve redução dos teores de FDA. 
As silagens de trigo e de aveia-preta mostraram redução nos teores de HEM, enquanto o triticale e a aveia-branca apresentaram aumento com o aumento no número de cortes. A redução no teor de HEM pode ter ocorrido pelo consumo dessa fração, uma vez que, dentre os três constituintes da FDN, a hemicelulose é a que possui maior potencial de digestão (Nussio et al., 2011), o que poderia ser aproveitado para a rebrota. O aumento no teor de HEM, por sua vez, pode ter ocorrido pelo fato de que o regime de cortes possibilitou o aumento de perfilhamento (Lemaire e Chapman, 1996), o que gerou aumento de HEM e diminuição de FDA para as forragens. De qualquer modo, fica evidente que cada cereal respondeu de forma distinta para os componentes da parede celular.

Com relação ao teor de $\mathrm{PB}$ das silagens, o trigo, o triticale e a cevada apresentaram as maiores concentrações, enquanto a aveia-branca e a aveia-preta apresentaram as menores, independentemente do regime de cortes. Além disso, o aumento no número de cortes foi significativo $(\mathrm{P}<0,05)$ para o trigo e a cevada e resultou em redução no teor de PB. Para a concentração de $\mathrm{MM}$, as silagens de cevada, aveia-branca e aveia-preta registraram os maiores valores, embora para o sistema com um corte no período vegetativo os materiais não apresentassem diferença significativa $(\mathrm{P}>0,05)$ para esse parâmetro. Com o aumento no número de cortes, foi possível observar, para o trigo, a aveia-branca e a aveia-preta, aumento nos teores de $\mathrm{PB}$, o que pode ser atribuído à composição morfológica das plantas.

Em comparação com os dados de literatura, os resultados encontrados para a cevada $(8,35 \%)$ são inferiores aos encontrados por Huuskonen (2013) $(10,1 \%)$ e superiores aos encontrados por Meinerz et al. (2011) (7,41\%). Já Lehmen et al. (2014) encontraram valor bastante próximo aos observados no presente trabalho $(8,40 \%)$. De modo geral, a cevada apresenta esses altos teores de PB em virtude de um programa de melhoramento intenso, no qual foram descobertos genes que influenciam tanto a quantidade como a qualidade da proteína desse cereal (Bumbieris Jr. et al., 2011). A cevada também apresentou os maiores valores de matéria mineral, porém inferiores aos relatados por Huuskonen (2013) (6,80 contra 4,23\%).

Conforme citado anteriormente, o aumento no número de cortes gerou decréscimo nos valores de PB e aumento na concentração de MM. Isso ocorre devido à necessidade de consumo de nutrientes para a rebrota, sobretudo de nitrogênio, o que, por sua vez, impacta sobre o teor de proteína. Além disso, aumentando o número de cortes, há decréscimo da área foliar, sendo esta responsável pela maior quantidade de proteína da planta. Juntamente a isso, os teores de matéria mineral, pelo efeito de concentração, tendem a ser superiores, sendo este um efeito previamente esperado (Buxton e O'kiley, 2003).

$\mathrm{Na}$ Tab. 2, são demonstrados os valores médios de temperatura e de $\mathrm{pH}$ das silagens submetidos a diferentes manejos de corte, após a abertura do silo. Pode-se observar que as silagens de cevada, aveia-branca e de aveia-preta apresentaram maiores temperatura e $\mathrm{pH}$. Vale a ressalva de que nenhuma das silagens registrou valores de temperatura superior à temperatura ambiente da sala em que foram armazenadas $\left(25^{\circ} \mathrm{C}\right)$.

Tabela 2. Temperatura média e $\mathrm{pH}$ médio das silagens de cereais de inverno submetidas a diferentes manejos de corte, após a abertura do silo

\begin{tabular}{cccccc}
\hline \multirow{2}{*}{ Regime de cortes } & \multicolumn{5}{c}{ Cereais de inverno } \\
\cline { 2 - 6 } & Trigo & Triticale & Cevada & Aveia- branca & Aveia- preta \\
\hline Sem cortes & $23,46 \mathrm{~b}$ & $23,58 \mathrm{~b}$ & $23,69 \mathrm{ab}$ & $24,08 \mathrm{a}$ & $23,76 \mathrm{ab}$ \\
Um corte & 23,72 & 23,78 & 23,48 & 23,57 & 23,57 \\
Dois cortes & $23,70 \mathrm{ab}$ & $23,53 \mathrm{~b}$ & $23,69 \mathrm{ab}$ & $23,53 \mathrm{~b}$ & $23,76 \mathrm{a}$ \\
\hline \multicolumn{5}{c}{$\mathrm{pH}$} \\
Sem cortes & $4,01 \mathrm{Bb}$ & $4,10 \mathrm{~b}$ & $4,43 \mathrm{~b}$ & $5,58 \mathrm{a}$ & $5,21 \mathrm{a}$ \\
Um corte & $4,72 \mathrm{ABab}$ & $4,17 \mathrm{c}$ & $4,15 \mathrm{c}$ & $4,46 \mathrm{~b}$ & $4,76 \mathrm{a}$ \\
Dois cortes & $5,04 \mathrm{Aa}$ & $4,46 \mathrm{c}$ & $4,50 \mathrm{c}$ & $4,44 \mathrm{c}$ & $4,88 \mathrm{~b}$ \\
\hline
\end{tabular}

Médias seguidas de letras minúsculas para linha diferem entre si pelo teste de Tukey a 5\%. ${ }^{1}$ Temperatura ambiente da sala mantida a $25^{\circ} \mathrm{C}$. 
Para o $\mathrm{pH}$ médio, no sistema sem cortes, os maiores valores encontrados foram para a silagem de aveia-branca e de aveia-preta (5,58 e 5,21 , respectivamente). Para o manejo com um corte, a silagem de aveia-preta também apresentou maiores valores de $\mathrm{pH}$ dentre os materiais avaliados. No entanto, para o manejo com dois cortes no estádio vegetativo, a silagem de trigo foi a que apresentou o maior $\mathrm{pH}$.

Esse comportamento da temperatura e do $\mathrm{pH}$ tem implicância direta na quantidade de horas para a perda da estabilidade aeróbia das silagens, como pode ser observado na Fig. 1.
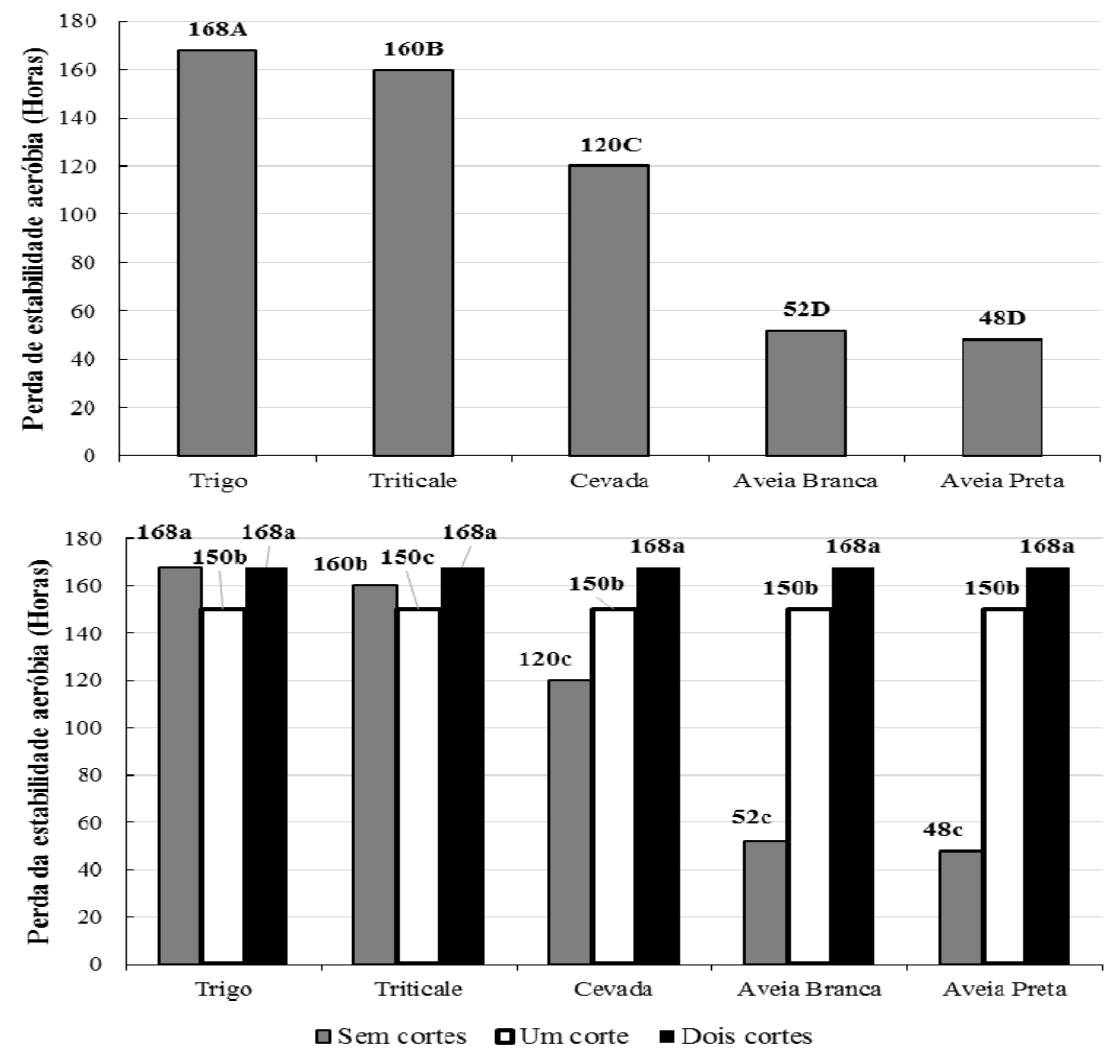

Figura 1. Avaliação da estabilidade aeróbia de silagens de cereais de inverno submetidas a um sistema integrado de produção de forragem verde e posterior produção de silagem.

Na análise da Tab. 2 e da Fig. 1, podem-se destacar as silagens de aveia-branca e de aveiapreta, no sistema sem cortes, uma vez que apresentaram a menor estabilidade aeróbia dentre todos os cereais avaliados.

Notadamente, conforme supracitado, em situações em que há menores quantidades de nutrientes, a estabilidade aeróbia tende a ser maior (Jobim et al., 2009). O oposto pode ser verificado no sistema sem cortes, uma vez que a cevada, a aveia-branca e a aveia-preta perderam estabilidade e apresentaram maiores $\mathrm{pH}$ médios.

Dentre as silagens, o trigo se destacou por apresentar maior estabilidade aeróbia. Tal fato pode ser justificado pela flora epifítica, a qual é predominantemente composta por microrganismos heterofermentativos ( $\mathrm{Ni}$ et al., 2015). A fermentação mediada por esses tipos de microrganismo ocasiona efeitos positivos sobre a estabilidade aeróbia, ou seja, previne deterioração da matéria seca depois da abertura do silo, uma vez que a produção de ácido acético e de 1,2 propanodiol, que posteriormente se transforma em ácido propiônico, e ambos possuem efeito antifúngico, atuando em leveduras, os principais microrganismos espoliadores da silagem (Pahlow et al., 2003; Rooke e Hatfield, 2003). 
Embora não se tenham avaliado os produtos de fermentação no presente experimento, Bumbieris Jr. et al. (2010), ao avaliarem silagens de triticale em cultivo singular ou consorciado com leguminosas, observaram uma alta produção de ácido acético do triticale quando em cultivo isolado. Tal fato pode corroborar a alta estabilidade aeróbia encontrada por este material.

\section{CONCLUSÕES}

O regime de cortes alterou a composição nutricional e a estabilidade aeróbia das silagens de cereais de inverno, sendo que houve comportamentos distintos entre os materiais. As silagens de triticale e de cevada apresentaram menor variação na composição nutricional com o aumento no número de cortes. A silagem de trigo, por sua vez, destacou-se como o material com maior estabilidade aeróbia.

\section{REFERÊNCIAS}

BORTOLINI, P.C.; SANDINI, I.; CARVALHO, P.D.F.; MORAES, A.D. Cereais de inverno submetidos ao corte no sistema de duplo propósito. Rev. Bras. Zootec., v.33, p.45-50, 2004.

BUMBIERIS JUNIOR, V.H.; JOBIM, C.C.; EMILE, J.C. et al. Aerobic stability of triticale silage in single culture or in mixtures with oat and/or legumes. Rev. Bras. Zootec., v.39, p.23492356, 2010.

BUMBIERIS JUNIOR, V.H.; OLIVEIRA, M.R.; BARBOSA, M.A.F.; JOBIM, C.C. Use of winter cultures for forage conservation. In: DANIEL, J.L.P.; NUSSIO, L.G. INTERNATIONAL SYMPOSIUM ON FORAGE QUALITY AND CONSERVATION, 2., 2011, São Pedro. Procedings... Piracicaba: Fealq, 2011. p.65-84.

BUXTON, D.R.; O’KILEY, P. Preharvest plant factors affecting ensiling. In: BUXTON, D.R.; MUCK, R.E.; HARRISON, J.H. (Eds.). Silage science and technology. Madison: Soil Science Society of America, 2003. p.199-250.

CAPPELLE, E.R., VALADARES FILHO, S.C., SILVA, J.F.C., CECON, P.R. Estimativas do valor energético a partir de características químicas e bromatológicas dos alimentos. Rev. Bras. Zootec., v.30, 1837-1856, 2001.
CARLETTO, R.; NEUMANN, M.; LEÃO, G.F.M. et al. Efeito do manejo de cortes sucessivos sobre a produção e qualidade de grãos de trigo duplo propósito. Rev. Acad. Cienc. Anim., v.13, p.127-135, 2015.

CARTAS climáticas do Paraná. Versão 1.0. [s.1.]: IAPAR, 2000. CD-ROM.

CARVALHO, G.G.P.; PIRES, A.J.V. Organização dos tecidos de plantas forrageiras e suas implicações para os ruminantes. Arch. Zootec., v.57, p.13-28, 2008.

CARVALHO, P.C.F.; SANTOS, D.T.; GONÇALVES, E.N. et al. Forrageiras de clima temperado. In: FONSECA, D.M.; MATURSCELLO, J.A. Plantas forrageiras. Viçosa: UFV, 2013, p.494-537.

CHERNEY, J.H.; CHERNEY, D.J.R. Assessing silage quality. In: BUXTON, D.R.; MUCK, R.E.; HARRISON, J.H. (Eds.). Silage science and technology. Madison: Soil Science Society of America, 2003. p.141-198.

FONTANELI, R.S.; FONTANELI, R.S.; SANTOS; H.P. et al. Rendimento e valor nutritivo de cereais de inverno de duplo propósito: forragem verde e silagem ou grãos. Rev. Bras. Zootec., v.38, p.2116-2120, 2009.

GOERING, H.K.; VAN SOEST, P.J. Forage fiber analysis: apparatus reagents, procedures and some applications. Washington: Agricultural Handbook, 1970. 379p.

HASTENPFLUG, M.; BRAIDA, J.A.; MARTIN, T.N. et al. Cultivares de trigo duplo propósito submetidos ao manejo nitrogenado e a regimes de corte. Arq. Bras. Med. Vet. Zootec., v.63, p.196-202, 2011.

HUUSKONEN, A. Performance of growing and finishing dairy bulls offered diets base on whole crop barley silage with or without protein supplementation relative to a grass silage-based diet. Agric. Food Sci., v.22, p.424-434, 2013.

JOBIM, C.C.; NUSSIO, L.G.; REIS, R.A., SCHIMIDT, P. Avanços metodológicos na avaliação da qualidade da forragem conservada. Rev. Bras. Zootec., v.36, p.101-119, 2007. 
JOBIM, C.C.; SILVA, M.S.; CALIXTO JUNIOR, M. Challenges in the utilization of high moisture grains silages for ruminants. In: INTERNATIONAL SYMPOSIUM ON FORAGE QUALITY AND CONSERVATION, 1., 2009, Piracicaba. Proceedings... Piracicaba: [FEALQ], 2009. p.91-108.

KUNG JUNIOR, L.; ROSINLOON, J.R.; RANJIT, K. Microbial populations, fermentation and-products, and aerobic stability of corn silage treated with ammonia or a propionic acid-based preservative. J. Dairy Sci., v.83, p.1479-1486, 2000 .

LEHMEN, R.I.; FONTANELI, R.S.; FONTANELI, R.S.; SANTOS, H.P. Rendimento, valor nutritivo e características fermentativas de silagens de cereais de inverno. Ciênc. Rural, v.44, p.1180-1185, 2014.

LEMAIRE, G.; CHAPMAN, D. Tissue flows in grazed plant communities. In: HODGSON, J.; ILLIUS A.W. The ecology and management of grazing systems. Wallingford: CAB International, 1996. p.3-37.

MEINERZ, G.R.; OLIVO, J.C.; VIÉGAS, J. et al. Silagem de cereais de inverno submetidos ao manejo de duplo propósito. Rev. Bras. Zootec., v.40, p.2097-2104, 2011.

NASCIMENTO JUNIOR, D.; VILELA, H.H.; SOUSA, B.M.L.; SILVEIRA, M.C.T. Fatores que afetam a qualidade de plantas forrageiras. In: REIS, R.A.; BERNARDES, T.F.; SIQUEIRA, G.R. Forragicultura: ciência, tecnologia e gestão de recursos forrageiros. Jaboticabal: Multipress, 2013. p.409-424.

NI, K.; WANG, Y.; CAI, Y.; PANG, H. Natural lactic acid bacteria population and silage fermentation of whole-crop wheat. Asian Aust. J. Anim. Sci., v.28, p.1123-1132, 2015.
NUSSIO, L.G.; CAMPOS, F.P.; LIMA, M.L.M. Metabolismo de carboidratos estruturais. In: BERCHIELLI, T.T.; PIRES, A.V.; OLIVEIRA, S.G. (Eds.). Nutrição de ruminantes. 2.ed. Jaboticabal: Funep, 2011. p.193-238.

PAHLOW, G.; MUCK, R.E.; DRIEHUIS, F. et al. Microbiology of ensiling. In: BUXTON, D.R.; MUCK, R.E.; HARRISON, J.H. (Eds.). Silage science and technology. Madison: Soil Science Society of America, 2003. p.31-94.

ROOKE, J.A.; HATFIELD, R.D. Biochemistry of ensiling. In: BUXTON, D.R.; MUCK, R.E.; HARRISON, J.H. (Eds.). Silage science and technology. Madison: Soil Science Society of America, 2003. p.95-135.

ROSÁRIO, J.G.; NEUMANN, M.; UENO, R.K. et al. Produção e utilização de silagem de trigo. Rev. Bras. Tecnol. Apl. Cienc. Agrar., v.5, p.207218, 2012.

SAS user's guide, version 6, 4.ed. Cary: SAS, 1993. v.2, $943 p$

SILVA, D.J.; QUEIROZ, A.C. Análise de alimentos: métodos químicos e biológicos. 3.ed. Viçosa: UFV, 2009. 235p.

TAYLOR, C.C.; KUNG JR., L. The effect of Lactobacillus buchneri 40788 on fermentation and aerobic stability of high moisture corn in laboratory silos. J. Dairy Sci., v.85, p.126-1532, 2002.

VAN SOEST, P.J.; ROBERTTSON, J.B.; LEWIS, B.A. Methods for dietary fiber, neutral detergent fiber, and nonstarch polysaccharides in relation to animal nutrition, J. Dairy Sci., v.74, p.3583-3597, 1991.

WEINBERG, Z.G.; CHEN, Y.; SOLOMON, R. The quality of commercial wheat silages in Israel. J. Dairy Sci., v.92, p.638-644, 2008. 